\title{
CROSS CULTURAL VARIATION OF QUESTIONING IN NEWS INTERVIEWS - A CASE OF POST-QUESTION ELABORATION IN CHINESE NEWS INTERVIEWS
}

\author{
Hongqiang Zhu and Tong Chen
}

\begin{abstract}
Questioning practice in news interviews has long been a central concern in the current studies of media discourse analysis in terms of its role in maintaining journalistic neutralism. Questions are usually structured into two forms: simple and complex one. In western news interviews, prefatory statements in complex questions are sufficiently examined in previous studies. Drawing on Conversation Analysis as methodology, this paper examines the questioning practice of English news interviews (i.e., Dialogue) aired in Chinese context and captures the post-question elaboration as a noticeable variant particularity in questioning practice in Chinese news interviews. Post-question elaborations are recognized in terms of the formal features in question design and their functions in the interviewer-interviewee interaction and further categorized into three types: first, post-question elaboration being evaded; second, post-question elaboration being answered along with the question; third, post-question elaboration being answered with question itself being evaded. This analysis reveals that post-question elaborations appear mostly to be associated with the informational contents negatively implicated in the question design and serve not only to contextualize the question itself but also to justify the act of questioning on the part of the interviewer.
\end{abstract}

\section{Keywords}

news interview, question design, conversation analysis, post-question elaboration, Chinese context

\section{Introduction}

Questioning practice in news interviews has long been a central interest of linguists and other social scientists exploring the role of journalists in performing and maintaining journalistic ethical norms. In particular, neutralism and adversarialism as the twin journalistic codes have been widely researched in studies of news interviews (Clayman 1988, 1992, 1993, 2002, Clayman \& Heritage 2002a, 2002b, Eströma 2009, Heritage 1985, Montgomery 2007, 2008, 2011, Rendle-Short 2007) and the focus of such research is the collaboration of question-answer turn-taking. On the one hand, the primary requirement for a journalist is to maintain his or her neutral posture in professional practice, and the basic issues are usually initiated and realized through question-answer 
activities; on the other hand, news interview questioning is not - and cannot be - strictly neutral. Questions unavoidably encode attitudes and points of view (Harris 1986), so interviewers are always faced with accusations of being biased or partial. Question design has become a central issue explored, along with the tradition of conversation analysis in discourse studies (Clayman \& Heritage 2002a, Greatbatch 1988, Heritage 1985, Heritage \& Greatbatch 1991, Heritage \& Roth 1995, Montgomery 2005).

The news interview as a genre has undergone many changes in its historical development. As noted in Clayman and Heritage (2002a), both in America and Britain, although differences and similarities exist when comparing their trajectories of development, the style of news interviews has generally changed from being deferential to being adversarial. As to the generic evolution of the news interview, Montgomery (2011) maintained that the news interview in Britain is also shifting towards 'argument.' These assertions are drawn in principle on the examination of interviewer-interviewee interactions in news interview programs. In those previous studies, question-answer activities were closely examined because the interviewer and interviewee exercised collaboratively the pre-allocated turns while fulfilling their roles in different and changing styles. However, whatever journalistic style the interview as a platform takes, investigating how the interaction of question-answer is formed linguistically is an essential enquiry.

The underlining structure of the news interview is described in Clayman and Heritage (2002a), where questioning is closely examined, especially its formal structure and the practices implicated in the maintenance of the interviewer's neutralism and how the interviewer adopts an adversarial stance and exerts pressure on the respondent in his or her question design, while not compromising his or her neutral posture. Because of the subject matter set in the agenda of news interviews, the formal features of standard broadcast news interviews are still evolving with a combination of features of other styles, such as 'argumentative or confrontational exchanges' in topical debate shows (Hutchby 1996, Tolson 2001), 'argument' or even 'belligerence' in hybrid political news interviews (Hutchby 2011a, 2011b), or 'assertiveness' adopted by Interviewer in UK general election interviews. Tolson (2012) suggested that the concept of neutralism has been internationally variable in some contemporary political interviews. In particular, he noted, in the British context, in contrast to American political interviews, fewer questions but more questioning statements were adopted by interviewers in UK election interviews. On the other hand, "adversarial interviewing has always involved some use of interviewer assertion" and such practice increased in the late 1990s (Tolson 2012: 45). 
In western news interviews, Clayman and Heritage (2002a) not only analyzed the different dimensions of questioning but also suggested that the shift toward the use of complex question design has been relatively marked in both the United States and the United Kingdom from the 1950s to the present. In particular, they claimed that the manifest function of prefaced questions is to provide context for the subsequent question to "overhearing" audience members (Clayman \& Heritage 2002a: 195-196). As Clayman and Heritage (2002a) suggested, the prefatory statement of a question normally works to provide background information to the audience; meanwhile, it can be used to make the agenda of a question "more complex, constraining, or problematic" (ibid.: 201).

In the analysis of question design by Heritage and Clayman (2002a), the 'prefaced question' is carefully constructed. However, the statement or elaboration after a question remains loosely discussed, although the researchers stated that, when analyzing how preference is conveyed through interrogative, "preference is established by a statement prior to the interviewer's question. A similar effect can be achieved by a statement positioned after the question (...)" (ibid.: 216). In the present paper, the statement positioned after the question is termed post-question elaboration. Therefore, post-question elaboration in questioning practice, which has received insufficient research attention, needs to be systematically mapped and investigated.

Departing from the literature on news interviews in a western context, in this paper, we examined the news interview in Chinese news media and investigated some particulars in the Chinese context. In our findings, unlike western interviewing styles, interviewers' questioning tends to be mild and less adversarial, and post-question elaboration helps to foreground the role of being indirect in this situated discourse. Post-question elaboration as additional information to the question, in this sense, may also involve contextualizing or tightening the questioning agenda set by the interviewer. Therefore, one of the purposes of the present study is to determine how post-question elaboration works in question-answer activities in news interviews.

Considering the above information, this study is largely concerned with question design in English news interviews within a Chinese context. The following two research questions guided this study:

1. How does the interviewer formulate his or her question, and what is the relationship between post-question elaboration and the question itself?

2. How does the interviewee's reply orient to the interviewer's question design? 


\section{Initial recognition of post-question elaboration}

According to the 'turn component' in journalistic questioning, Clayman and Heritage (2002a) classified questions in news interview into two categories simple or complex. The complex question is a prefaced form involving additional statements that lead up to the question itself. They argued that the function of prefatory sentences is to supply background information for the news audience, presenting it as a simple fact known to the parties, and establishing a context for the subsequent question. Clayman and Heritage claimed that the delivery of prefaced questions involves collaboration between interviewers and interviewees. Normally, the interviewee would withhold any response until a recognizable question has been produced by the interviewer. However, few studies have focused on news interviews to determine the components that form a turn and the function of each component in the whole turn of questioning. For the present study, the data appear to indicate that there is far more complexity of structure in question design in English news interviews in a Chinese context.

In these data, a question usually takes a prefaced form. In addition, a recognizable and unique feature within a question is that extra formulations appear after a recognizable question has been clearly produced. An example of this form of question follows (IR - interviewer, IE - interviewee):

Example 1 CCTV-News Dialogue, Edition 321, 2010

IR: Yangrui IE: Sebastián Piñera, Chile’s President

IR: China's rapid rise (.) is viewed FAR and WIDE $\quad 1$

as er the most EXTRAORDINARY and 2

PHENOMENAL thing (.) in the twenty first century (.) 3

when you meet with your Chinese counterpart 4

Mr. Hu Jingtao (.) our president (1.0) 5

what would you tell him if possible (.) 6

about images of China for people in Latin America $\quad 7$

because er (1.0) those in the west might say 8

hey hey hey this is the late comer to our WEALTHY CLUB 9

and er no we are not (1.0) well PREPARED yet er 10

it could be a THREAT for our (.) established international (.) 11

economic political order $\quad 12$

IE: we:: have followed very closely (2.0) what was happening in 13

China thirty eight years ago (.) China decided to change its 14

development model (.) and established what they call 15

OPENESS and DEVELOPMENT (.) and before they (1.0) 16

became an open country (.) and started to TRADE with the whole world (.) 17

since then (.) China has been growing FASTER than (.) 18

the rest of the world (...) 
The interviewer's questioning in this interview has a noticeable feature: the question is prefaced and posed with additional information. This feature corresponds with the move structure in classroom discourse proposed by Sinclair and Coulthard (1992), which consists of signals, prehead, head, posthead, and select clue occurring in a post-head position. Sinclair and Coulthard recognized the function of each move in the system of teaching interaction. This finding is helpful in analyzing the moves of questioning in news interviews. Drawing on Sinclair and Coulthard's analysis of IRF structure in classroom interaction and the study of question design by Clayman and Heritage (2002a), we examined our data to determine a new structure of question design. Based on our observation, a question can consist of the following moves: (a) address as signal, (b) prefatory statement, (c) question, and (d) post-question elaboration:

[Address + Prefatory Statement + Question + Post-Question Elaboration]

In structural terms, the question move is obligatory, whereas the other moves of the address - signal, prefatory statement, and post-question elaboration - are optional, subsidiary to the question itself.

In this case, lines 1-12 constitute a whole question, and lines 6-7 are a $\mathrm{WH}-$ question. A recognizable question (head) is formatted after a long preface in lines 1-5. The address as signal does not necessarily appear because this turn exchange occurs in the course of interviewing. It is striking that the question has such a long elaboration after it has been successfully produced. To better show the statement after a question, one more example is provided:

Example 2 CCTV-News, Dialogue, 28/02/2011

IR: Yangrui IE: Professor Korpela,Tsinghua Univerist

IR: Professor Korpela (.) um (1.0)

what do you think of the issue of (.) 21

the foreign exchange re regime err: $\quad 22$

when it comes to the err newly-elected government in Brazil (.) 23

they are certainly NOT very HAPPY about the 24

err err (.) such kind of currency pressure which may 25

have a lot to do with the domestic politics in US?

IE: It certainly a hot topic and it continues to be a hot topic (...)

Starting with an address to Professor Korpela, the interviewer moves with his question design. The question design is recognized as an effective WH-question (lines 21-23: "what do you think of the issue of the foreign exchange regime . . ."), which is followed with a stretch of utterances as additive information (lines 24-26). The formulation in lines $24-26$, "they are certainly not very happy about ...." is clearly produced after the WH-question is successfully offered to the 
interviewee. In this case, we identify the formulations in lines $24-26$ as 'postquestion elaboration'.

Our concern is the role of the long statement after a question. How does it function in question design? These two cases seem to be different from the cases in contemporary western news interviews, in which 'adversarialness' and direct question styles are imbedded (Clayman \& Heritage 2002a, 2002b) and probably contribute to the shaping of the English news interviews in the Chinese context.

Post-question elaboration is extra information that follows the question and adds details to the question during question-setting. It usually appears as a relatively independent part after a question that is clearly articulated in both form and content. It needs to be distinguished from question repair. As indicated by Clayman and Heritage (2002a), question repair is quite different because it refers to a question that is not clearly and completely articulated or it is intended to shift footing while the interviewer needs to revise the question itself (Clayman \& Heritage 2002a). Seen from its formal structure, post-question elaboration seems to be relatively independent of the question itself in form. The post-additional information is produced after a question is relatively clearly formulated; without it, this question per se is still making sense grammatically. Another distinction should be made concerning the complex questioning used in western news interviews (Clayman \& Heritage 2002a). Post-question elaboration as extra information can be understood as not necessarily having a close connection with the question itself.

As suggested in the "western" context, prefaced statements in complex questions are essential resources for resetting the context for the following questions, providing not merely background for a question but also "experiential context for the interviewee's answer" (Clayman \& Heritage 2002a: 195). However, closer examination of the data in western news interviews indicates that, on the grammatical level, some questions take the form of a long clause that closely works as an attribute or complement to some component of the question. The following examples illustrate this point (cases 35 and 37):

'IR: How d'you sum up the me:ssage. that this decision is sending to the Soviet?' (ibid.: 220) and also the case 37

'IR: How could you talk about human rights when Doctor Sakharov has been banished .hhh without

(.) tria::1 (.).hh er and without as we can see any form of just (.) process. (ibid.: 220) 
As seen in the above examples, the questions are in the form of complex sentences in which a 'that' or 'when' clause seems to be 'additional' information or definition for the question. Syntactically and semantically, the clause serves as either an attributive clause or adverbial clause to make the utterance pragmatically complete. These clauses are necessarily bound to the component of the question to provide an overt and elaborate turn-relevance place for the interviewee. In addition, the subjects of inquiry, like "message" and "human right", are very general and need further definition. Without the clausal supplement, the question will not be recognized and understood properly. In Chinese news interviews, in some similar cases, the questioning is incomplete unless additional information, like an attributive or other type of clause, is attached. Questioning in this way is not included in the post-question elaboration data because the post-question elaboration should have a relatively loose relationship with the question per se.

Nevertheless, we do not necessarily base post-question elaboration on the grammatical structure but on its function in the discourse acts in the interaction. As Sinclair and Coulthard (1992: 4) suggested, spoken discourse is approached on the basis of moves and discourse acts because the "move is the smallest free unit although it has a structure in terms of acts". In addition, they argued that grammatical structure is not sufficient to determine which discourse act a particular grammatical unit realizes. That is, one needs to take into account both relevant situation information and position in the discourse.

\section{Methodology}

The analytical method adopted in this study is qualitative and descriptive. The data comprised in the corpus derive from a news interview program aired on China Central Television (CCTV), namely Dialogue (aired in English). We examined five episodes: Yang Rei's interview with Chile's president, Sebastián Piñera; Yang Rei's interview with Tony Blair, the ex-British PM; Yang Rui's interview with Charles Tang, chairman of the Brazil-China Chamber of Commerce and Industry, and Prof. Sirkka Korpela of Tsinghua University; Tian Wei's interview with Michelle Bachelet, the Secretary UN Women; and Tian Wei's interview with Wang Binbin, the manager of the climate change team at Oxfam Hong Kong. Post-question elaboration is not a necessary component in every question design in the collected Chinese news interview. However, it cannot be neglected. To investigate how much the post-question elaboration weighs in the interviewers' choices in designing their questions, we conducted a small-scale quantitative analysis. Basically, the interviewers' turns are calculated, and the questions with post-question elaboration are singled out. As Table 1 indicates, among the five episodes of Dialogue examined, post-question elaboration accounted for 20 per 
cent of the total interviewers' turns, a noticeably high percentage considering the varieties of questioning techniques that could be employed. Thus, examining post-question elaboration, which remains relatively under-researched, should prove interesting and of great significance.

\begin{tabular}{|l|c|c|c|}
\hline \multicolumn{1}{|c|}{ Programs } & $\begin{array}{c}\text { Overall } \\
\text { questions }\end{array}$ & $\begin{array}{c}\text { Questions with } \\
\text { post-question } \\
\text { elaboration }\end{array}$ & $\begin{array}{c}\text { Frequency of } \\
\text { post-question } \\
\text { elaboration }\end{array}$ \\
\hline $\begin{array}{l}\text { Yang Rui's interview with Charles Tang } \\
\text { and Prof. Sirkka Korpela }\end{array}$ & 18 & 4 & $22.22 \%$ \\
\hline $\begin{array}{l}\text { Yang Rei's interview with Sebastián } \\
\text { Piñera }\end{array}$ & 19 & 3 & $15.79 \%$ \\
\hline Yang Rei's interview with Tony Blair & 18 & 4 & $22.22 \%$ \\
\hline $\begin{array}{l}\text { Tian Wei's interview with Michelle } \\
\text { Bachelet }\end{array}$ & 17 & 3 & $17.65 \%$ \\
\hline $\begin{array}{l}\text { Tian Wei's interviewer with Wang Binbin } \\
\text { and the other }\end{array}$ & 18 & 4 & $22.22 \%$ \\
\hline Total & 90 & 18 & $20.00 \%$ \\
\hline
\end{tabular}

Table 1: Summary of the questions in the programs

\section{Data analysis}

As Table 1 above shows, post-question elaboration plays an essential role when interviewers frame their questions. However, what is the function of postquestion elaboration? What is its relationship with the question, and how has it been treated by the interviewee? Based on observation of 18 examples of questions with post-question elaboration, three categories were identified, with six examples serving as evidence for each category.

\subsection{Post-question elaboration being evaded}

As mentioned above, post-question elaboration with its information load may work in a similar way as the question preface. The following extract from an interview with the Chile's President about the bilateral relationship between China and Chile and the inspiring miner rescue operation is an example.

Example 3 CCTV-News Dialogue, Edition 321, 2010

IR: Yangrui IE: Sebastián Piñera, Chile's President 
IR: China's rapid rise (.) is viewed FAR and WIDE $\quad 1$

as er the most EXTRAORDINARY and 2

PHENOMENAL thing (.) in the twenty first century (.) 3

$\begin{array}{ll}\text { when you meet with your Chinese counterpart } & 4\end{array}$

Mr. Hu Jingtao (.) our president (1.0) 5

what would you tell him if possible (.) 6

about images of China for people in Latin America $\quad 7$

because er (1.0) those in the west might say 8

hey hey hey this is the late comer to our WEALTHY CLUB 9

and er no we are not (1.0) well PREPARED yet er 10

it could be a THREAT for our (.) established international (.) 11

$\begin{array}{ll}\text { economic political order } & 12\end{array}$

IE: we:: have followed very closely (2.0) what was happening in 13

$\begin{array}{ll}\text { China thirty eight years ago (.) China decided to change its } & 14\end{array}$

development model (.) and established what they call 15

OPENESS and DEVELOPMENT (.) and before they (1.0) 16

became an open country (.) and started to TRADE with the whole world (.) 17

since then (.) China has been growing FASTER than (.) 18

the rest of the world (...)

In this extract, the interviewer's question is formulated in the formal structure discussed previously: prefatory statement + question + post-question elaboration. Post-question elaboration appears as a subordinate clause that sets a contrastive context for the question by stating the ongoing attitude of China being a "threat", along with its rapid rise. The elaboration of China's negative acceptance by some westerners is prefaced with a causal conjunction because but with no hint of causal relevance to the question shown in the elaboration. In association with the question preface, the term because can be perceived as having the same semantic effect as the adversative conjunction $b u t$, which projects a negative statement contrary to the expectation of the prior question. Specifically, if the post-question elaboration were moved ahead of the question and the conjunction because were replaced with but, the question would become as follows and would be easier to understand:

IR: China's rapid rise (.) is viewed FAR and WIDE as er the most EXTRAORDINARY and PHENOMENAL thing (.) in the twenty first century (.) but er (1.0) those in the west might say hey hey hey this is the late comer to our WEALTHY CLUB and er no we are not (1.0) well PREPARED yet er it could be a THREAT for our (.) established international (.) economic political order when you meet with your Chinese counterpart

Mr. Hu Jingtao (.) our president (1.0) what would you tell him if possible (.) about images of China for people in Latin America 
Such a conflicting stance is also salient in the interviewer's description of China's rise as "far and wide" and "the most extraordinary and phenomenal" in the question preface, as opposed to the descriptions of "late comer" and "threat" in the question elaborations. The post-question elaboration featured with its negative prominence would easily draw the interviewee's attention to answer or at least respond to it. However, the interviewee follows the question itself by recalling China's opening and reforming process and approving China's huge development instead of attending to the detailed post-question elaboration. Brown and Levinson's politeness theory (1987) may have a play in the interactional choice made by the interviewee. Thus, the negative proposition encoded in the post-question elaboration is likely to incur a face-threatening act. By responding to it, the interviewee automatically would expand the "China threat" in great detail, thereby threatening the interviewer's positive face. Although the question itself is buried in the middle of the turn and seems to be posed in a relatively insignificant manner, the interviewee immediately finds the question and makes a direct response to it by conveying his idea of China's rise. In doing so, he properly avoids the face-to-face embarrassment that could have come after the "China threat".

A similar case occurred in the interview with Mr. Tony Blair, the former Prime Minister of the United Kingdom, when commenting on the recent SinoUK relationship shortly after the Beijing Olympic Games:

Example 4 CCTV-News Dialogue, 29 Oct 2010: Blair's Life and Faith IR: Yangrui IE: Tony Blair, former British Prime Minister

IR: what do you think other fundamental reasons 28 \begin{tabular}{ll}
\hline to your knowledge for China to be so powerful yet (.) & 29
\end{tabular} we fell apart almost at the end of Qing dynasty and the Opium war 30 broke out of course (.) that's a dark chapter 31 between our u:m two countries. 32

IE: [yeah, um but I think I think er: as the speech 33 once Premier Wen Jiabao put it very very well (.) 34 China has ALWAYS done well when it opened up to the world (.) 35 it's always done badly when it's closed up (1.0) 36 and this is the thing actually it's true for most countries (0.6) 37 y' know the DANDER for the countries like MINE 38 today is with the passing of e:r our imperial past (.) 39 we get nervous, we get insecure and we close DOWN the world right (0.8) $\quad 40$ countries always do best when they got an open mind and attitude the reason 41 why China can suddenly get throu:gh in the last (0.6) thirty or (.) or so years 42 (.) this is because your policy changed that $(0.7)$ you opened it up 
The interviewee is asked to give his perception of China's speedy power resurgence by a question posed in a rather simple structure, with no prefatory statement or embedded clause. The post-question elaboration takes shape as an entirely independent part of the turn, with no conjunction connected to the question, although considering the meaning, the description of the post-question elaboration establishes a contradictory context to the question. For instance, the "dark chapter" is introduced as opposed to China being "so powerful." Accordingly, if the interviewee responds to the phrase dark period, he might risk threatening the interviewer's positive face. To answer this question, the interviewee refers to Premier Wen's speech to evaluate the country's developing process and present his idea that opening up is the main solution for a country to regain power. By introducing the third-party statement, the interviewee properly avoids a direct face-to-face threatening situation.

In both cases, the interviewer overtly shows his alignment with China by using the inclusive pronouns in questioning, for instance, "our president" in Example 1 and "We fell apart" in Example 3. By doing so, he establishes his stance in the conversation. In terms of its functions, post-question elaboration shares some similarities with question preface. On the one hand, elaboration, as the term suggests, offers background information for the question, for the benefit of the audience; on the other hand, elaboration with a negative connotation exerts pressure on the interviewee in responding to the questions, setting an expectation the answer will be opposite to the negative connotation. In this situation, the constraining statement in the post-question elaboration is used to make a striking difference between "we" and "the other" and "now" and "past," in turn endorsing what is presented as "we" and "now" by the interviewer.

\subsection{Post-question elaboration answered along with the question}

In addition to the features of contextualizing and constraining, the postquestion elaboration can also work to foreground the "goodness" of either the interviewee or the interviewer.

Example 5 CCTV-News Dialogue, Edition 321, 2010

IR: Yangrui IE: Sebastián Piñera, Chile's President

IR: $\quad$ By the way (.) Mr. President (.) this is a very good story (.) 43 a FASCINATING STORY for the whole WORLD (.) 44 u:m (1.5) have you EVER WAIVERED or BLI:NKED um since (.) NOBODY was one hundred percent sure 46 whether er: the thirty three miners were still ALIVE $\quad 47$ at the critical moment (3.0) = 48

IE: um, they were 49 
IR: = because someone PERSUADED you to keep 50 distance from (.) the very tricky question of the 51 rescue cooperation cos otherwise $\quad 52$ your whole reputation might be er: $\quad 53$ at mercy of something totally UNCERTAIN 54

IE: almost (.) all my advisers at the beginning (.) they 55 told me don't get involved (.) this will 56

IR: that's unbelievable $\quad 57$

IE: this will end as a tragedy (.) it's almost impossible to find them 58 and even more impossible to rescue them. $\quad 59$

They are so deep down in the mouth. The rock is so hard. 60

We don't have the technologies. $\quad 61$

And I say look if this is not us (.) who and therefore i said no question. 62

We'll commit ourselves one hundred percent (...) 63

In this example, the interviewer's question is structured as address + prefatory statement + question + post-question elaboration. After a formal address signal, "Mr. President," the interviewer evaluates what the president has said as a "good" story and further reinforces his comment by stressing it is "a fascinating story for the whole world". This act indicates the interviewer's acknowledgement and alignment with the interviewee. With this footing in mind, the interviewer inquires about the mental state of the president in terms of the miner rescue work. The question is initially buried in a long clause, explaining the uncertainties of the situation (lines 47-49). To be noted here is the subsequent exchange of the interviewer and interviewee after the question, when the interviewer steps in to interrupt the interviewee's response and offers another possible reason (lines 5155) for the President to be excused for staying away from the event. Although the elaboration carries a negative description of the situation - "nobody was one hundred percent sure" and "some persuaded you to keep distance from uncertainty" - which could orient the interviewee to contradict the negative connotation, the post-question elaboration functions in a different way from the preceding examples.

For example, the interviewee responds to it by admitting most of the advice was for him not to get involved considering the critical challenge of both adverse natural conditions and technological deficiencies. The interviewee shows his disagreement with those issues posited in the post-question elaboration and his determination to recover the miners: "commit one hundred percent." In answering both the post-question elaboration and the question, the interviewee strengthens his positive face by setting up the contrast between the circumstances and his choice. In this respect, the post-question elaboration works to foreground the resolution and fortitude of the Chilean president.

A similar case appears in an example from the interview with Tony Blair in which he is asked about Britain's image to be presented to the world in the 
coming Olympic Games in 2012. The question itself is concise in its structural sense with no preface but with a post-question clause. Unlike the prior cases, although the clause is prefaced by the conjunction "because," the interviewer does not put the elaboration in a contrasting or causal stance with the question. Rather, the demonstration of Beijing volunteers' creditable performance stands as an independent model, implicating that "We did a great job. How about you?" The interviewee, as a response, speaks highly of Beijing Olympic volunteers doing "a lot of good for the whole images of China" and afterwards turns to what he thinks of the British image as a "multicultural, multi-racial society and multi-faces society". The responsive action is produced in a harmonious rather than a competitive manner, with reciprocal agreement from both parties to foreground the "goodness" of Chinese volunteer. By participating in this evaluation, the interviewer expresses Britain's wish to be at least as good as its Chinese counterpart.

Example 6 CCTV-News Dialogue, 29 Oct 2010: Blair's Life and Faith IR: Yangrui IE: Tony Blair, former British Prime Minister

IR: What kind of image of Britain do you want your (.) 65 British volunteers to present to the rest of world 66 because um (.) at the end of Beijing Olympics a lot of th:e er those 67 who followed Beijing Olympics competition to say (.) 68 we should give the biggest medal (.) to the volunteers 69

IE: I think wha: what Beijing Olympics did put a lot of volunteers in quite $\quad 70$ interesting (.)ya: er a new dimension (0.8) ya: um so (0.8) 71 I think the volunteers from Beijing Olympics did a lot of good for $\quad 72$ the whole images of China (.) er: um for us (.) u: you know (0.6) 73 I:I have our volunteers I am not sure what will happen to present $\quad 74$ the British images of today (.) you know (.) of course (.) people like 75 to come to Britain to see (.) hhh the buildi:ngs th:e history (.) 76 the traditions and all of that but (.) today in London (.) 77 it is very MULTIcultural um MULTI-racial society en and multi-faces $\quad 78$ $\begin{array}{ll}\text { society (.) so London might y'know as um um as the same same } & 79\end{array}$ might ten year old boy (.) he has (?) friends Muslims ()um Hindus $\quad 80$ um different varieties of Christian (.) it is the same to (.) actually 81 the Buddhists everywhere um so (.) you know (.) 82 so this is the way of British today also.

In both cases, the post-question elaboration works to contextualize the question but does not constrain or tighten the question agenda. The interviewee's responsive action in these cases is usually focused on both the elaboration and the question. As Heritage and Clayman (2002a) suggested, an interviewee's responding to the preface can be considered an evasive strategy to sidetrack the question. In this case, the interviewee's answer to the post-question elaboration 
is not necessarily an action of evasion but a supportive endorsement of the question itself. Here, the post-question elaboration, as mentioned previously, is used to foreground the positive image or quality of either the interviewer or the interviewee.

\subsection{Post-question elaboration answered with question being evaded}

In the above two categories, post-question elaboration works either to constrain or to endorse the question. No matter how insignificantly the question is buried, the interviewee's response still returns to the question. However, the following example offers a new scenario in which the post-question elaboration substitutes for the function of questioning, causing the original question to be neglected by the interviewee.

Example 7 CCTV-News Dialogue, 08 Nov 2011: Women's Rights in Today's World IR: Tianwei

IE: Michelle Bachelet, the secretary of UN Women and former Chilean President

IR: um (.) looking at you (.) personally (.) $\quad 84$

I can get a lot of inspiration ALREADY 85

you are ei: a socialist label you as and also you are a SINGLE-MOTHER $\quad 86$

$\begin{array}{ll}\text { in a CATHOLIC country from Chile ORIGINALLY (.) } & 87\end{array}$

you are also the FIRST (.) FEMALE PRESIDENT of the 88

$\begin{array}{ll}\text { COUNTRY (.) and you wer::e (.) as a young (.) women (.) } & 89\end{array}$

have to be on exile because of some political (.) complicated 90

political situation with you:(r) FAMILY later coming back (.) 91

as the FIRST DEFENSE secretary of your $\uparrow$ COUNTRY $\downarrow() \quad$.

CONGRATULATIONS on that as well hhh (.) 93

SO (.) bu(t) the thing IS (.) how many WOMEN would have 93

chances as you do (.) and a lot of them are SAYING (.) you are 95

gifted (.) you AR::E ORIGINALLY (.) HAVING (.) certain family 96

BACKGROUND you are having the OPPORTUNITIES to EDUCATION. 97

IE: of course that's true (.) and that's why I became a doctor because we get (.) 98

I used to study in a public school in my country (.) 99

I saw I I I I don't become I don't come from a rich family (.) 100

just middle calss and I have all these opportunities 101

because I had great parents (...)

In this case, the interviewee is asked about the current situation of women's rights in Chile. The question is framed as a B-event statement instead of an interrogation, although it achieves the pragmatic force of questioning. It is launched in a long preface covering the interviewee's unusual personal experience as a "single mother in a Catholic country," originally "the first female president," and now "coming back as the first defence secretary" after being "in exile." The 
prefatory sentences have well contextualized the interviewee's extraordinary achievement as a female. However, signalled by but, the interviewer shifts his alignment in questioning the reasons for such achievement. The challenging statement is salient in the post-question elaboration as the interviewer invokes an anonymous collective third party ("a lot of them") to disclose the preferable family background of the interviewee. In doing so, he implies the interviewee's success is largely attributed to the superior material foundation that she had over most of her female peers.

The post-question elaboration works similarly to its counterparts in Examples 1 and 3 to elaborate the preface in a contrastive manner with a constraining effect on the interviewee to offer a response opposite to the negative implication. Nevertheless, unlike Examples 1 and 3, in which post-question elaboration negative statements are associated with "we", as endorsed by the interviewer, in Example 7, the unfavorable situation is directly channelled to the interviewee, causing her to risk threatening her own interests or her positive face. Thus, it is plausible for the interviewee to respond to the post-question elaboration first to save her own face. The interviewee's responsive action to the post-question elaboration clarifies that she does not "come from a rich family" and, in fact, "studied in a public school," indicating success was achieved by her own efforts so her female peers could also access success even without financial support.

Interestingly, the question itself about "how many women would have chance as you do" is actually impossible to answer without scientific research. Even if the question were changed to a new one derived from the logic of the conversation - "You are great as a woman but that's because of your superior family background. Will other women in your country have the chance as you do to be educated?" - the interviewee may still find it difficult to address the question. The negative answer "No" would render the interviewee's effort in promoting women's rights meaningless while the affirmative answer "Yes" would result in an overt dilemma that it is not possible for every woman to have the same rights because of the discrepancy between the rich and poor. Therefore, the original question leaves the interviewee with no choice but to answer the post-question elaboration as an evasive strategy.

Example 8 CCTV-News Dialogue 21 Oct 2011: Climate Change-New Call for Action IR: Tian wei IE: Wang Binbin: Manager of climate change team at Oxfam Hong Kong

IR: before you ask everybody to take an action 
because people are NOT happy about just (1.0) you know propaGANDA (.) 106 people are interested only in evidence-based action 107

IE: em: hmm (1.0) yes (.) you are right (.) actually I think it's NOT a propaganda 108 you know (.) we just have an IPCC report (.) and I think now climate change 109 is a REAL fact in front of all of us (.) so for ChiNESE we've experienced 110 climate change ALready and I have a survey result here and more than ninety 111 percent of Chinese they are- these are um these are um they experienced $\quad 112$ Climate change (0.8) so now for example in Beijing (.) we we have 113 experienced heat pollution air pollution these kinds of pollutions actually (.) 114 the big background is about the climate change right and in rural area, th: the 115 extreme weather (.) has affected the people's (.) life so=

IR: $\quad=$ smog is not it's not extreme weather (.) it is rather related only to pollution 117

(.) I don't (.) people do not see necessarily many of the direct link between 118 the

smog and climate change (.) can you help us to understand the scientific link between these two if you SAY these are closely related $\uparrow$

Example 8 is a second example of the post-question elaboration replacing the question in terms of the interviewee's response. In this extract, the interviewee, a government representative on climate change, is interviewed to justify the government environmental policy.

The interviewer's question is concisely structured as question + post-question elaboration. The interviewee is asked to give "hard evidence" to support her call for all citizens to "take actions" on climate change because, as stressed in the post-question elaboration, people are "not happy" about the empty slogan and need "evidence-based action". Similar to Example 7, via the negative statement introduced in the post-question elaboration, the interviewer directly challenges the interviewee, who is the key person providing the government scientific statistics on climate change, implying that she might be a propagandist for the government environmental policy. The interviewee's face is explicitly damaged by such an implicit accusation, so her first priority is to respond to the negative post-question elaboration by denial: "it's not propaganda". Her explanatory effort lasts for the whole turn, thereby side tracking her response to the question. As a government representative, the interviewee needs to be very careful in coping with the question. She is not expected to risk her own face even while she is responsible for not compromising the government's interest by giving "hard evidence" that may go against current environmental policy. Therefore, by answering the post-question elaboration instead of the question itself, the interviewee avoids the dilemma that may endanger both her and the government's interests. However, this evasive action is noticed by the secondround of inquiry on "the scientific link" (lines 119-120). 


\section{Concluding discussion}

The preceding analysis has shown ways in which interviewers depart from the question design with a carefully woven pattern, as suggested by Clayman and Heritage (2002a), that is, with variations on post-question elaboration. To conclude, interviewers shape the style of their interviews by orienting a question in a mild and less critical way to mitigate the pressure of questioning and lessen the degree of being adversarial. The less adversarial style of the news interview in the Chinese context has some resemblance to the deferential style used in U.S. and U.K. contexts five decades ago. However, divergences between the past western and contemporary Chinese patterns remain, and those divergences are the main findings of this paper: First, in a structural sense, the question as an action is formulated in more complex moves/acts within the Chinese context, and post-question elaboration plays an important part in engineering the interviewerinterviewee turns. Second, in terms of discourse function, post-question elaboration as a means to add background information serves to contextualize the question so that the audience has a better understanding of the situation the question addresses. In addition, post-question elaboration functions to legitimate the interviewers. As most of the post-question elaborations are attributed to a third party, such as "because those in the west might say" (Example 1), "because ... a lot of those ... would say" (Example 6), and "a lot of them are saying" (Example 7), the interviewers justify their acts of questioning by presenting them as though they are being asked on behalf of a majority. Meanwhile, post-question elaboration also helps to direct the interviewee to respond to the question in various ways.

Another noticeable finding is that the content the post-question elaboration covers is, to a large extent, negatively associated, as can been seen from five of six examples in this study (Examples 1, 3, 4, 7, and 8). As the analysis shows, post-question elaboration often introduces a relatively contrastive context to the question and, by doing so, places pressure on the interviewee to engineer particular answers, usually opposite to the negative connotation (Examples 1, $3,4,7$, and 8). However, even with the same negative constraints, the ways interviewees respond to the post-question elaborations are strikingly different, thus altering the function of the post-question elaboration in specific scenarios. In these examples, post-question elaborations are likely to be addressed when they are likely to endanger the interviewees' interests (Examples 7 and 8), when they can display the positive quality or goodness of the interviewee (Example 4), or when they cannot do harm to the interviewer's interests (Example 6). 
Conversely, post-question elaborations that are likely to threaten the interviewer's face or do no good to the interviewer would be evaded (Examples 1 and 3). Such responsive choices reflect the interviewees' cooperative efforts to maintain the conversation and avoid leading it to an awkward and embarrassing moment. Structurally speaking, post-question elaboration can also show interviewees' collaboration in the production of interviewers' questions. As stated earlier, in a conversation, interviewees are expected to withhold any response until a recognizable question has been produced (Clayman \& Heritage 2002a). However, in terms of the cases not only prefaced but also post-elaborated, the interviewees show their collaborative patience to wait for the whole turn to be completed even after the question is clearly produced.

In this study, post-question elaboration is viewed as a significant component in questioning turns. Unlike those instances that might occasionally appear in the contemporary western news interview, post-question elaboration can be noticeably identified in the Chinese data. This is a significant variant of the prototypical question structure captured in the current literature. This study, based on a small amount of data, is only a tentative exploration of the forms and functions of post-question elaboration. For further studies, examining the forms and functions of post-question elaboration in connection with the shape of the news culture in the Chinese context would be worthwhile.

\section{References}

Clayman, S. (1988) 'Displaying neutrality in television news interview.' Social Problems 35 (4), 474-492.

Clayman, S. (1992) 'Footing in the achievement of neutrality: The case of news interview discourse.' In: Drew, P. and Heritage, J. (eds) Talk at Work. Cambridge: Cambridge University Press. 163-198.

Clayman, S. (1993) 'Reformulating the question: A device for answering/not answering questions in news interviews and press conferences.' Text \& Talk 13 (2), 159.

Clayman, S. (2002). 'Disagreements and third parties: Dilemmas of neutralism in panel news interviews.' Journal of Pragmatics 34 (10), 1385-1401.

Clayman, S. and Heritage, J. (2002a) The News Interview - Journalists and Public Figures on the Air. Cambridge: Cambridge University Press.

Clayman, S. and Heritage, J. (2002b) 'Questioning presidents: Journalistic deference and adversarialness in the press conference of Eisenhower and Regean.' Journal of Communication 52 (4), 749-755.

Eströma, M. (2009) 'Announced refusal to answer: A study of norms and accountability in broadcast news interview.' Discourse Studies 11, 681-702.

Greatbatch, D. (1988) 'A turn-taking system for British news interviews.' Language in Society 17, 401-430.

Harris, S. (1986) 'Interviewers' questions in broadcast interviews.' In: Wilson, J. and Crow, K. (eds) Besfast Working Papers in Language and Linguistics 8. Ulster: University of Ulster. 50-85. 
Heritage, J. (1985) 'Analyzing news interviews: Aspects of the production of talk for an 'overhearing' audience.' In: van Dijk, T. (ed.) Handbook of Discourse Analysis 3, Discourse and Dialogue. London: Academic Press. 95-119.

Heritage, J. and Greatbatch, D. (1991) 'On the institutional character of institutional talk: The case of news interviews.' In: Boden, D. and Zimmerman, D. (eds) Talk and Social Structure. Cambridge: Polity Press. 93-137.

Heritage, J. and Roth, A. (1995) 'Grammar and institution: Questions and questioning in the broadcast news interview.' Research on Language and Social Interaction 28 (1), $1-60$.

Hutchby, I. (1996) Confrontation Talk. Arguments, Asymmetries and Power on Talk Radio. Hillsdale, NJ: Erlbaum.

Hutchby, I. (2011a) 'Non-neutrality and argument in the hybrid political interview.' Discourse Studies 13 (3). 349-365.

Hutchby, I. (2011b) 'Doing non-neutral: Belligerent interaction in the hybrid political interview.' In: Ekstrom, M. and Patrona, M. (eds) Talking Politics in Broadcast Media: Cross-Cultural Perspectives on Political Interviewing, Journalism and Accountability. Amsterdam and Philadelphia: John Benjamins. 115-134.

Montgomery, M. (2005) 'The discourse of war after 9/11.' Language and Literature 14 (2), 149-180.

Montgomery, M. (2007) The Discourse of Broadcast Talk. London and New York: Routledge.

Montgomery, M. (2008) 'The discourse of the broadcast news interview: A typology.' Journalism Studies 9 (2), 1-19.

Montgomery, M. (2011) 'Chapter 2: The accountability interview, politics and change in UK public service broadcasting'. In: Ekstrom, M. and Patrona, M. (eds) Talking Politics in Broadcast Media: Cross-Cultural Perspectives on Political Interviewing, Journalism and Accountability. Amsterdam and Philadelphia: John Benjamins. 33-56.

Rendle-Short, J. (2007) 'Neutralism and adversarial challenges in the political news interview.' Discourse \& Communication 1 (4), 387-406.

Sinclair, J. and Coulthard, M. (1992) 'Towards an analysis of discourse.' In: Coulthard, M. (ed.) Advances in Spoken Discourse. London: Routledge. 1-34.

Tolson, A. (ed.) (2001) Television Talk Shows: Discourse, Performance, Spectacle. Mahwah, NJ: Lawrence Erlbaum Associates.

Tolson, A. (2012) "YYou'll need a miracle to win this election" (J. Paxman 2005): Interviewer assertiveness in UK general elections 1983-2010.' Discourse, Context \& Media 1 (1), 45-53.

\section{Transcription Conventions}

(.)

(...)

Capitalisation

The underlined Italics

$\uparrow$ pause of half a second or less

pause of timed over half a second

ellipsis of utterance

stress of words or syllables

question

post-question elaboration

rising tone

falling tone

lapse of sound 
Hongqiang Zhu obtained his Ph.D. in English Linguistics, under the supervision of Prof. Martin Montgomery, from the University of Macau and is currently Lecturer of English Linguistics in the College of Foreign Studies, Jinan University, Guangzhou, China. His research interests lie in the area of discourse analysis, pragmatics and conversation analysis, concentrating mainly on media discourse and news discourse. He has published several articles in Discourse, Context \& Media, Discourse and Society, Discourse and Communication etc.

Address: Hongqiang Zhu, College of Foreign Studies, Jinan University, Guangzhou, China. 510632. [e-mail: hongqiangzhu@163.com]

Tong Chen is a Ph.D. candidate under the supervision of Prof. Martin Montgomery, University of Macau and is currently Lecturer in School of Foreign Languages, Southwest University of Political Science and Law, Chongqing, China. Her research interests lie in media discourse analysis by drawing upon various analytic techniques such as conversation analysis, pragmatics and critical discourse analysis.

Address: Tong Chen, Department of English, FAH, University of Macau; School of Foreign Languages, Southwest University of Political Science and Law, Chongqing, China. 401120. [e-mail: corychen22@gmail.com] 